\title{
Análise dos anticorpos vibriocidas e aglutinantes na população urbana do Município do Manacapuru/AM (1992/1993)
}

\author{
Analysis of vibriocidal and agglutinating antibodies in the \\ population of the urban area of Manacapuru, \\ Amazonas State, Brazil (1992-1993) \\ Eloisa da Graça do Rosario Gonçalves e Ernesto Hofer
}

Resumo Foi realizado um estudo sorológico em 1.196 indivíduos residentes na área urbana do município de Manacapuru/AM, visando analisar o perfil dos anticorpos vibriocidas e aglutinantes. Empregou-se o procedimento de amostragem aleatória sistemática na obtenção da amostra populacional. Um ano após, obteve-se uma $2^{a}$ amostra de soro de 120 indivíduos (10\% da amostra inicial), escolhidos aleatoriamente entre os participantes do inquérito, com o objetivo de avaliar o comportamento dos anticorpos nesse intervalo de tempo. Foram empregados os métodos de microtitulação de anticorpos vibriocidas e de soroaglutinação em tubos. A associação entre os anticorpos estudados foi determinada pelo coeficiente de correlação, calculado com base na distribuição de freqüência dos títulos detectados. A análise dos resultados revelou forte correlação positiva entre os anticorpos $(r=1,0)$ e queda nos títulos em grande proporção das amostras após um ano.

Palavras-chaves: Cólera. V. cholerae 01. Anticorpos vibriocidas e aglutinantes.

Abstract A serological study was carried out involving 1.196 individuals residents in the urban area of Manacapuru - Amazonas, to evaluate the behavior of vibriocidal and agglutinating antibodies. A sistematic random sampling procedure was employed to obtain the sample. A year later a 2nd sample of serum was obtained from 120 individuals selected among the participants of the survey. Vibriocidal antibodies microtitulation and seroagglutination in tubes were employed. The correspondence between the studied antibodies was determined by the correlation coefficient calculated according to the frequency of the titles detected. The analysis of the results revealed positive correlation between the antibodies $(r=1.0)$ and a decrease in titles in a large proportion of the positive samples one year later.

Key-words: Cholera. V. cholerae O1. Vibriocidal and agglutinating antibodies.

Curso de Pós-Graduação em Medicina Tropical e Laboratório de Zoonoses Bacterianas, do Instituto Oswaldo Cruz, Rio de Janeiro, RJ. Apoio financeiro do CNPq.

Endereço para correspondência: Dra. Eloisa da Graça do Rosario Gonçalves. Rua 1, 728 - São Francisco, 65076-320 São Luis, MA.

Recebido para publicação em 14/11/96. 
A cólera vem apresentando um novo perfil clínico-epidemiológico a partir da década de 60. Esta modificação, resultante do envolvimento do biotipo El Tor de Vibrio cholerae OI na produção da doença, caracteriza-se pelo processo de endemização 11 assim como pela maior proporção de casos leves, moderados e de infecção assintomática quando comparada com a doença produzida pelo biotipo clássico29.

A prevalência de infecção tende a ser subestimada quando se elege como critério diagnóstico o isolamento e identificação do vibrião colérico. Estudos sorológicos demonstram, contudo, que a real difusão do bacilo pode ser muito mais ampla do que revelam as análises bacteriológicas8 1020 .

Neste sentido, alguns métodos sorológicos, em especial a pesquisa de anticorpos vibriocidas e aglutinantes produzidos contra o antígeno somático, ao lado da pesquisa da anti-toxina, têm sido amplamente empregados. Estes métodos foram desenvolvidos a partir dos trabalhos de Pfeiffer (o qual observou a lise rápida dos agentes patogênicos quando inoculados na cavidade abdominal de cobaias imunizadas contra a cólera) e de Gruber e Duhram, os primeiros a observarem o fenômeno da aglutinação ao misturarem suspensões de bacilos da febre tifóide com soro de animais imunizados 25 .

O emprego rotineiro do método da aglutinação torna-se-ia problemático, contudo, em decorrência das dificuldades na preparação do antígeno e padronização da técnica26 o que, em parte, foi superado com as modificações introduzidas por Goodner e cols 18 , dentre as quais o uso de suspensões vivas do bacilo, como antígenos. Com isto o método tornou-se o padrão com o qual outros métodos sorológicos passaram a ser comparados 5 .

Já o uso sistemático da pesquisa de anticorpos vibriocidas foi introduzido por Serkowiski em 190625, o qual observou a propriedade bacteriolítica de soros imunes quando misturados com suspensões do bacilo e complemento. Modificações foram introduzidas à técnica por vários pesquisadores 152123 , sendo o método da microtitulação dos anticorpos desenvolvido por Benenson e cols 4 , os quais ressaltam as vantagens do uso rotineiro do método como procedimento diagnóstico.

A sensibilidade e especificidade de ambos os métodos têm sido determinadas em estudos de sorologia pareada em pacientes com cólera naturalmente adquirida e bacteriologicamente comprovada, variando entre 90 e 97\%4 1326 , o que os torna valioso instrumento de investigação epidemiológica.

No presente estudo procurou-se avaliar o comportamento de anticorpos produzidos contra o V. cholerae 01 em uma amostra da população residente na área urbana de Manacapuru/AM (atingida pela epidemia de cólera, de outubro de 1991 a fevereiro de 1992, quando foram registrados 69 casos bacteriologicamente comprovados ${ }^{17}$ ), através dos referidos métodos de pesquisa de anticorpos vibriocidas e aglutinantes, estabelecendo-se como objetivos específicos determinar os títulos dos anticorpos, avaliar a existência de correlação entre os diferentes anticorpos pesquisados e reavaliar o perfil destes anticorpos em 10\% dos participantes do estudo, um ano após a realização do inquérito.

\section{MATERIAL E MÉTODOS}

Área de estudo. O município de Manacapuru, está localizado no centro da Amazônia Brasileira, numa altitude de 34 metros acima do nível do mar, tendo como limítrofes os municípios de Novo Airão, Iranduba, Beruri, Manaquirí, Caapiranga e Anamã. A sede minucipal situa-se à margem esquerda do Rio Solimões, na confluência deste com o Rio Manacapuru, distante da capital $79 \mathrm{~km}$ em linha reta 1 . O perímetro urbano é composto de 8 bairros, tendo sido subdividido em 42 setores, como parte do plano de operacionalização do trabalho de vigilância sanitária exercido pela Fundação Nacional de Saúde.

Conforme apurado em inquérito realizado em agosto de 1990 e atualizado em novembro de 1991 pela Fundação Nacional de Saúde (FNS), a população urbana consta de 34.607 habitantes, sendo o número de domicílios avaliado em 6.892, com média de ocupação de 5 pessoas por unidade.

Obtenção da amostra. Foi empregado o processo de amostragem aleatória sistemática, abordando-se 240 grupos familiares, distribuídos em um terço dos 42 setores nos quais a área de estudo encontra-se dividida.

A coleta de todo material do estudo foi feita em visitas domiciliares, no período de março a julho de 1992. Com o objetivo de reavaliar o comportamento dos anticorpos após um ano, 
obteve-se uma $2^{\text {a }}$ amostra de soro de 120 indivíduos ( $10 \%$ da amostragem inicial) escolhidos aleatoriamente entre os participantes do inquérito.

As amostras sanguíneas foram obtidas por punção venosa periférica, utilizando-se tubos de vacuteiner. A fração sérica foi separada por centrifugação a $3.000 \mathrm{rpm}$ durante 15 minutos e mantidas a $-20^{\circ} \mathrm{C}$.

Análise sorológica. Foram empregados os métodos de microtitulação de anticorpos vibriocidas, segundo técnica modificada por Benenson e cols 4 e de soroaglutinação $O$, conforme proposto por Goodner e cols18, empregando-se como antígenos as cepas VC12 Ogawa e VC-13 Inaba (CDC-Atlanta/USA).

A soroaglutinação $\mathrm{OH}$ foi incluída a fim de avaliar a possível sensibilização por outros sorovars da espécie $V$. cholerae 6729.

Avaliou-se a existência de correlação entre os anticorpos pesquisados através do cálculo do coeficiente de correlação, tomando-se por base a distribuição de freqüência dos títulos encontrados.

\section{RESULTADOS}

Foram abordados 240 domicílios nos quais residiam um total de 1.441 pessoas. Em decorrência de recusas ou ausência de membros das famílias no momento das visitas, foram obtidas 1.196 amostras de soro. Dentre os participantes, $687(57,4 \%)$ indivíduos pertenciam ao sexo feminino e 509 (42,5\%), ao masculino, com idade variando de 2 a 90 anos.

A distribuição de freqüência dos títulos dos anticorpos estudados está representada na Tabela 1.

O coeficiente de correlação calculado entre os anticorpos vibriocidas e aglutinantes $O$, assim como entre os anticorpos aglutinantes $O$ e $\mathrm{OH}$ foi igual a um $(r=1)$, revelando significativa associação entre eles.

Os dados referentes aos 120 indivíduos

Tabela 1. Distribuição de freqüência dos títulos dos anticorpos vibriocidas e aglutinantes $\mathrm{O}$ e $\mathrm{OH}$ detectados nas 1.196 amostras séricas estudadas. Manacapuru/AM (1992).

\begin{tabular}{|c|c|c|c|c|c|}
\hline \multirow[t]{2}{*}{ Títulos } & \multicolumn{2}{|c|}{ Vibriocidas } & \multicolumn{2}{|c|}{ Aglutinantes $O$} & \multirow[t]{2}{*}{ Aglutinantes $\mathrm{OH}$} \\
\hline & $\mathrm{Og}$ & In & $\mathrm{Og}$ & In & \\
\hline$\overline{\mathrm{NR}}$ & 923 & 955 & 883 & 885 & 777 \\
\hline $1: 10$ & 53 & 45 & 63 & 55 & 82 \\
\hline $1: 20$ & 90 & 76 & 48 & 50 & 85 \\
\hline $1: 40$ & 55 & 60 & 80 & 89 & 111 \\
\hline $1: 80$ & 29 & 24 & 80 & 70 & 81 \\
\hline $1: 160$ & 17 & 12 & 29 & 34 & 34 \\
\hline $1: 320$ & 11 & 13 & 9 & 9 & 23 \\
\hline $1: 640$ & 9 & 5 & 4 & 3 & 3 \\
\hline $1: 1280$ & 9 & 5 & 0 & 1 & 0 \\
\hline $1: 2560$ & 0 & 1 & 0 & 0 & 0 \\
\hline
\end{tabular}

$\mathrm{Og}$ = Ogawa; In = Inaba; NR = não reagente.

Tabela 2. Distribuição de freqüência dos títulos de anticorpos vibriocidas detectados contra os antígenos Ogawa e Inaba em 120 indivíduos analisados nos dois períodos do estudo/Manacapuru (1992-1993).

\begin{tabular}{|c|c|c|c|c|c|c|c|c|}
\hline \multirow{3}{*}{ Títulos } & \multicolumn{4}{|c|}{$1^{\text {a }}$ amostra (1992) } & \multicolumn{4}{|c|}{$2^{\mathrm{a}}$ amostra (1993) } \\
\hline & \multicolumn{2}{|c|}{$\mathrm{Og}$} & \multicolumn{2}{|c|}{$\ln$} & \multicolumn{2}{|c|}{$\mathrm{Og}$} & \multicolumn{2}{|c|}{$\ln$} \\
\hline & $\mathrm{n}^{0}$ & $\%$ & $\mathrm{n}^{\circ}$ & $\%$ & $\mathrm{n}^{0}$ & $\%$ & $\mathrm{n}^{0}$ & $\%$ \\
\hline$\overline{N R}$ & 48 & 40,0 & 53 & 44,1 & 91 & 75,8 & 89 & 74,1 \\
\hline $1: 10$ & 25 & 20,8 & 30 & 25,0 & 10 & 8,3 & 18 & 15,0 \\
\hline $1: 20$ & 13 & 10,8 & 10 & 8,3 & 15 & 12,5 & 5 & 4,1 \\
\hline $1: 40$ & 12 & 10,0 & 17 & 14,1 & 3 & 2,5 & 6 & 5,0 \\
\hline $1: 80$ & 9 & 7,5 & 12 & 10,0 & 0 & 0 & 0 & 0 \\
\hline $1: 160$ & 5 & 4,1 & 4 & 3,3 & 1 & 0,8 & 1 & 0,8 \\
\hline $1: 320$ & 4 & 3,3 & 3 & 2,5 & 0 & 0 & 0 & 0 \\
\hline $1: 640$ & 2 & 1,6 & 2 & 1,6 & 0 & 0 & 0 & 0 \\
\hline $1: 1280$ & 2 & 1,6 & 2 & 1,6 & 0 & 0 & 1 & 0,8 \\
\hline Total & 120 & 100,0 & 120 & 100,0 & 120 & 100,0 & 120 & 100,0 \\
\hline
\end{tabular}

Og = Ogawa; In = Inaba; NR = não reagente. 
Tabela 3. Distribuição de freqüência dos títulos dos anticorpos aglutinantes O detectados em 120 indivíduos nos dois períodos do estudo/Manacapuru (1992-1993).

\begin{tabular}{|c|c|c|c|c|c|c|c|c|}
\hline \multirow{3}{*}{ Títulos } & \multicolumn{4}{|c|}{$1^{\mathrm{a}}$ amostra (1992) } & \multicolumn{4}{|c|}{$2^{\mathrm{a}}$ amostra (1993) } \\
\hline & \multicolumn{2}{|c|}{$\mathrm{Og}$} & \multicolumn{2}{|c|}{$\ln$} & \multicolumn{2}{|c|}{$\mathrm{Og}$} & \multicolumn{2}{|c|}{$\ln$} \\
\hline & $\mathrm{n}^{\circ}$ & $\%$ & $\mathrm{n}^{\circ}$ & $\%$ & $\mathrm{n}^{\circ}$ & $\%$ & no & $\%$ \\
\hline$\overline{N R}$ & 53 & 44,1 & 49 & 40,8 & 116 & 96,9 & 117 & 97,5 \\
\hline $1: 10$ & 14 & 11,6 & 12 & 10,0 & 2 & 1,6 & 1 & 0,8 \\
\hline $1: 20$ & 13 & 10,8 & 14 & 11,6 & 2 & 1,6 & 2 & 1,6 \\
\hline $1: 40$ & 20 & 16,6 & 25 & 20,8 & 0 & 0 & 0 & 0 \\
\hline $1: 80$ & 13 & 10,8 & 11 & 9,1 & 0 & 0 & 0 & 0 \\
\hline $1: 160$ & 6 & 5,0 & 9 & 7,5 & 0 & 0 & 0 & 0 \\
\hline $1: 320$ & 0 & 0 & 0 & 0 & 0 & 0 & 0 & 0 \\
\hline $1: 640$ & 1 & 0,8 & 1 & 0,8 & 0 & 0 & 0 & 0 \\
\hline Total & 120 & 100,0 & 120 & 100,0 & 120 & 100,0 & 120 & 100,0 \\
\hline
\end{tabular}

Og = Ogawa; In = Inaba; NR = não reagente.

reavaliados um ano após a realização do inquérito são apresentados nas Tabelas 2 e 3, onde pode ser observado que apenas pequena proporção das amostras (3,3\% para o sorotipo Ogawa e $2,5 \%$, para o Inaba) exibia atividade aglutinante $O$, em baixos títulos.

Quanto aos vibriocidas, maior número de soros permaneceu reagente quando comparado com a soroaglutinação. $\mathrm{Na}$ quase totalidade destas amostras, no entanto, os títulos dos anticorpos não ultrapassaram 1:20. Houve persistência do título inicial $(1: 1280)$ em apenas uma amostra, referente ao sorotipo Inaba.

\section{DISCUSSÃO}

A decisão de empregar dois métodos sorológicos (pesquisa de anticorpos vibriocidas e soroaglutinação), com o uso simultâneo de dois sorotipos de $\mathrm{V}$. cholerae $\mathrm{Ol}$ como antígenos, decorreu da maior sensibilidade que tal procedimento proporciona na detecção da resposta imunológica conforme observado em importante série de trabalhos2 410202226 .

Com base na literatura analisada verifica-se que os títulos dos anticorpos considerados indicativos de infecão pelo vibrião colérico variam amplamente entre os autores4 $58910141928 \mathrm{em}$ parte devido ao eventual encontro de anticorpos naturais em indivíduos sem história de exposição reconhecida ao $\mathrm{V}$. cholerae $\mathrm{Ol}$, o que dificulta a interpretação dos testes sorológicos.

Tem sido prática freqüente nessas pesquisas o emprego de sorologia pareada na fase aguda e convalescente da doença, considerando diagnóstico de infecção pelo vibrião colérico, o aumento de, pelo menos, quatro vezes nos títulos dos anticorpos.
Não tendo havido possibilidade da realização de sorologia pareada em nosso estudo, não foi fácil avaliar até que ponto os títulos dos anticorpos apresentados numa única tomada são representativos, de fato, de resposta imune específica ao vibrião colérico.

A cinética dos anticorpos aglutinantes e vibriocidas foi demonstrada, contudo, por vários autores3 510132628 , ficando claro que a resposta imune à cólera é caracteristicamente rápida, com os anticorpos atingindo títulos mais acentuados em torno do décimo dia da infecção, seguindose queda significativa no intervalo médio de 6 a 12 meses, o que, segundo Clements e cols10, torna possível um diagnóstico retrospectivo de infecção pelo $V$. cholerae 01 .

Comparando os dois tipos de anticorpos, Finkelstein 15 encontrou evidências de que a atividade vibriocida persiste por tempo mais longo, apresentando queda mais gradual nos títulos do que os anticorpos aglutinantes, o que pode ser constatado em nosso estudo, quando se compara o comportamento os anticorpos na análise feita um ano após o estudo inicial.

A interpretação dos testes sorológicos pode, ainda, assumir diferentes conotações de acordo com as circunstâncias epidemiológicas em que são realizados. Cash e cols 9 argumentam sobre a importância de se considerar o contexto ambiental, bem como a experiência prévia dos indivíduos submetidos aos estudos, com a doença. Neste sentido, ressaltamos o fato de que a presente investigação foi realizada em período imediato à ocorrência de epidemia de cólera, cerca de um século após o último registro da doença em nosso país, admitindo-se, por conseguinte, que o encontro de anticorpos 
vibriocidas e aglutinantes, nesta situação, possa estar refletindo resposta imune específica ao agente da doença.

É importante, contudo, registrar a falta de estudos sobre a etiologia das doenças diarréicas ocorridas na área de estudo, antes da epidemia de cólera, ou da possível circulação de outras bactérias capazes de induzir o aparecimento de anticorpos reagentes com o $\mathrm{V}$. cholerae $\mathrm{OI}$ na população12 16.

Não podendo afastar de todo esta possibilidade e visando reforçar a segurança de que os anticorpos detectados no estudo são dirigidos ao $\mathrm{V}$. cholerae $\mathrm{Ol}$, adotou-se a inclusão de aglutinação $\mathrm{OH}$, com o objetivo de avaliar a ocorrência de possíveis reações cruzadas resultantes da sensibilização por outros sorovars da espécie $V$. cholerae, os quais apresentam, uniformemente, a mesma estrutura antigênica flagelar6 727 , além da averiguação de queda nos títulos dos anticorpos pesquisados, doze meses após a realização do inquérito.

A associação positiva verificada entre a aglutinação $\mathrm{O}$ e $\mathrm{OH}(r=1,0)$ sugere que reações cruzadas com diferentes sorovars de $V$. cholerae possam ser excluídas, enquanto a negativação ou redução dos títulos dos anticorpos em grande proporção das amostras reagentes analisadas um ano após o inquérito, é compatível com a história natural da infecção por $V$. cholerae 01 .

A forte correlação constatada entre os anticorpos vibriocidas e aglutinantes $(r=1,0)$, está de acordo com os resultados obtidos por Barua e cols, Mosley e cols e Sack e cols3 22 26, em cujas experiências foram empregados os dois métodos simultaneamente. Este resultado reforça, a nosso ver, a validade do uso da metodologia empregada em estudos epidemiológicos.

\section{REFERÊNCIAS BIBLIOGRÁFICAS}

1. Álbum Cartográfico dos Municípios do Estado do Amazonas. Governo do Estado do Amazonas, 116p, 1983.

2. Bart KJ, Auq Z, Khan M, Mosley WH. Seroepidemiologic studies during a simultaneous epidemic of infection with El Tor Ogawa and classical Inaba Vibrio cholerae. Journal of Infectious Diseases 12 (suppl):17-24, 1970.

3. Barua D, Sack RB. Serological studies in cholera. Indian Journal of Medical Research 52:855-866, 1964.
4. Benenson AS, Saad A, Mosley WH. Serological studies in cholera. The vibriocidal antibody response of cholera patients determined by a microtechnique. Bulletin of the World Health Organization 38:277-285, 1968.

5. Beran GW. Serological studies on cholera. I. Antibody levels observed in vaccinated and convalescent persons. The American Journal of Tropical Medicine and Hygiene 13:698-707, 1964.

6. Bhattacharyya FK. Vibrio cholerae flagellar antigens: a serodiagnostic test, functional implications of $\mathrm{H}$-reactivity and taxonomic importance of crossrections within the Vibrio genus. Medical Microbiology and Immunology 161:29-41, 1975.

7. Bhattacharyya FK, Mukerjee S. Serological analysis of the flagelar or agglutining antigens of cholera and NAG vibrios. Annales de Microbiologie (Institute Pasteur) 125:167-181, 1974.

8. Blake PA. Epidemiology of cholerae in the Americas. Gastroenterology Clinics of North America 22:639660, 1993.

9. Cash AR, Music SJ, Libonati PJ, Snyder MJ, Wenzel RP, Hornick RB. Response of man to infection with Vibrio cholerae. I. Clinical, serological and bacteriologic responses to a know inoculum. Journal of Infectious Diseases 129:45-52, 1974.

10. Clements ML, Levine MM, Young CR, Black RE, Lim YL, Robins-Browne RM, Craig JP. Magnitude, kinetics and duration of vibriocidal antibody responses in North Americans after ingestion of Vibrio cholerae. Journal of Infectious Diseases 145:465-473, 1982.

11. Feachem RG. Environmental aspects of cholera epidemiology. Tropical Disease Bulletin 78:675-698, 1981.

12. Feeley JC. Somatic $O$ antigen relationship of Brucella and Vibrio cholerae. Journal of Bacteriology 99:645649, 1969.

13. Feeley JC, Diwitt WE. Immune response to Vibrio cholerae. In: Rose NR, Friedman H (eds) Manual of Clinical Immunology. 1st edition. American Society for Microbiology. Washington DC, p. 289-295, 1976.

14. Felsenfeld O, Dutta NK. A serological survey of cholera-free and cholera-infected areas. Journal of Tropical Medicine and Hygiene 75:209-212, 1972.

15. Finkelstein RA. Vibriocidal antibody inhibition analysis: a technique for the identification of predominant vibriocidal antibodies in serum and for the detection and identification of $V$. cholerae antigens. Journal of Immunology 89:264-271, 1962.

16. Gangarosa EJ, De Witt WE, Feeley JC, Adams MR. Significance of vibriocidal antibodies with regard to 
immunity to cholera. Journal of Infectious Diseases 121:36-43, 1970.

17. Gonçalves EGR, Loblein O, Chaia W, Hofer E. Estudo descritivo de 69 casos de cólera ocorridos na área urbana do município de Manacapuru/AM em 1991 1992. In: Resumos do XXIX Congresso da Sociedade Brasileira de Medicina Tropical, Fortaleza p. 208, 1993.

18. Goodner K, Smith HL, Stemper H. Serological diagnosis of cholera. Journal of Albert Einstein Medical Center 8:143-147, 1960.

19. Khan MV, Barua DK, Begum T, Shahidrullah M. Vibriocidal titre in cholera cases and contacts: its value in assessing endemicity of or susceptibility to cholera. Tropical and Geographical Medicine. 39:271-275, 1987.

20. McCormack WM, Islam S, Fahimuddin M, Mosley WH. A community study of innapparent cholera infections. American Journal of Epidemiology 89:658664, 1969.

21. McIntyre OR, Feeley JC. Passive serum protection of the infant rabbit against experimental cholera. Journal of Infectious Diseases 114:468-475, 1964.

22. Mosley WH, Benenson AS, Barua RA. A serological survey for cholera antibodies in rural East Pakistan. II. A comparison of antibody titres in immunized and control populations of cholera-vaccine field trial area and relation of antibody titre to cholera case rate. Bulletin of the World Health Organization 38:335-346, 1968.

23. Muschel LH, Treffers HP. Quantitative studies on bactericidal actions of serum and complement. I. A rapid photometric growth assay for bactericidal activity. Journal of Immunology 76:1-10, 1956.

24. Nalin DR, Morris Jr JG. Cholera and other vibrioses. In: Strickland GT (ed) Hunter's Tropical Medicine, 7th edition, WB Saunders Company, Philadelphia, p. 366-375,1991.

25. Pollitzer R. Cholera. World Health Organization. Série de Monografias, 43. Geneva, Switzerland, 1959.

26. Sack RB, Barua D, Saxena R, Carpenter CCJ. Vibriocidal and agglutinating antibody patterns in cholera patients. Journal of Infectious Diseases 116:630-640, 1966.

27. Sakazaki R, Tamura K, Gomez CZ, Sen R. Serological studies on the cholera group of vibrios. Japanese Journal of Medical Science and Biology 23:13-20, 1970.

28. Snyder JD, Allegra DT, Levine MM, Craig JP, Feeley JC, DeWitt WE, Blake PA. Serologic studies of naturally acquired infection with $V$. cholerae $O I$ in the United States. Journal of Infectious Diseases 143:182-187, 1981. 